\title{
Case studies of mental models in home heat control: Searching for feedback, valve, timer and switch theories
}

\begin{abstract}
An intergroup case study was undertaken to determine if: 1) There exist distinct mental models of home heating function, that differ significantly from the actual functioning of UK heating systems; and 2) Mental models of thermostat function can be categorized according to Kempton's (1986) valve and feedback shared theories, and others from the literature. Distinct, inaccurate mental models of the heating system, as well as thermostat devices in isolation, were described. It was possible to categorise thermostat models by Kempton's (1986) feedback shared theory, but other theories proved ambiguous. Alternate control devices could be categorized by Timer (Norman, 2002) and Switch (Peffer et al., 2011) theories. The need to consider the mental models of the heating system in terms of an integrated set of control devices, and to consider user's goals and expectations of the system benefit, was highlighted. The value of discovering shared theories, and understanding user mental models, of home heating, are discussed with reference to their present day relevance for reducing energy consumption.
\end{abstract}

\section{Keywords}

Mental Models; Home Heating; Device Models; Energy Consuming Behaviour; Usability

\subsection{Introduction}

Mental models can be thought of as internal constructs that explain human behaviour (Wickens, 1984; Kempton 1986). The notion has been associated with many domains over the last 20 years, including domestic (Kempton, 1986), transport (Weyman et al., 2005) and military (Rafferty et al., 2010). Mental Models have formed the basis of strategies to improve interface design (Carroll and Olson 1987; Williges, 1987; Norman 2002; Baxter , 2007; Jenkins et al. 2010), to promote usability (Norman, 2002; Mack and Sharples 2009; Jenkins et al. 2011; Branaghan et al., 2011; Larsson, 2012), and to encourage sustainable behaviour (Kempton, 1986; Sauer et al., 2009; Lockton et al., 2010) amongst many others. In 1986, Kempton described two distinct 'forms' of mental models of thermostat function that were prevalent in the population of that time. He proposed that the form of model held, could result in significant variations in the amount of energy consumed due to home heating, by promoting different patterns of manual thermostat adjustment. Currently in the UK, $25 \%$ of carbon emissions are from domestic customers, $58 \%$ of which is due to domestic heating. The UK has legislated to cut $80 \%$ of greenhouse gas emissions by 2050 (Climate Change Act, 2008). Since Kempton's study, almost three decades have passed and technology has changed. It seems appropriate, therefore, to explore if Kempton's (1986) shared theories can still be identified, and if so, to question if they remain relevant to design strategies targeted at combatting climate change.

The term 'mental model' is used in different domains to mean different things (Wilson \& Rutherford, 1989) and even within a domain, can be used to describe internal constructs that differ significantly in terms of content, function or perspective (Richardson \& Ball, 2009, Revell \& Stanton, 2012). The form of mental model descriptions may have similarities to the way other types of models (e.g. 
process models or logic models) that do not depict internal constructs, are represented, resulting in confusion when interpreting outputs. Specificity in the type of mental model is considered essential for commensurability when conducting research (Norman , 1983; Wilson \& Rutherford, 1989; Bainbridge , 1992; Revell \& Stanton, 2012). The authors ask the reader to bear the extended clarification of the way the term is used to this paper. The intention is to allow sufficient understanding to determine the relevance and applicability of the findings presented. This paper refers to mental models in three different ways: 1 ) in terms of its function; 2 ) in terms of its source, and; 3 ) in terms of its individuality.

In terms of function, the definition most fitting is a "device model". Kieras \& Bovair (1984) adopted this terminology to describe a mental model held by a user of how a device works. It includes a set of conceptual entities and their interrelationships (Payne , 1990). In this paper, the device of interest is the home heating system, and we seek to describe the conceptual entities and their interrelationships held by users. Device models, as a type of mental models, may be incomplete, inaccurate, and inconsistent (Norman, 1983). The authors believe that understanding where omissions, inaccuracies and inconsistencies occur in users device models of home heating, could provide insights into how to reduce energy consumption resulting from non-optimal operation.

In terms of its source, this paper adopts Norman's (1983) definition of a "User Mental Model"(UMM). He describes this as "the actual mental model [of a target system] a user might have", that can only be gauged by undertaking observations or experimentation with the user. In this paper we are seeking the model of the home heating system held internally by a user. As we cannot access this model directly, we have adopted a method appropriate to our aims to gain data to describe the user mental model.

In terms of the individuality of mental models, we also refer to Kempton's (1986) 'shared theory'. A 'shared theory' is derived by an analyst through the identification of similarities in separate UMMs of individuals. These individuals are within a social group, who may share similar types of individual goals. a 'shared theory' differs from concepts such as 'shared' or 'team' mental models that refer to shared knowledge structures within a team or group who are working towards group goals (Richardson \& Ball). The benefit of identifying shared theories of home heating, is broader reach when when targeting strategies, to combat climate change, at individuals within the home.

The 2 shared theories identified by Kempton (1986) were described as 'valve' and 'feedback'. Users with a valve shared theory, considered changes in the set point of their thermostat to be controlling the intensity of heat in their furnace, with the onus on the user to ensure a comfortable home temperature. Users with a feedback shared theory, considered it their responsibility merely to select the desired thermostat set point. The thermostat would maintain comfort in the home by controlling the boiler operation period, in response to measurements of house temperature. Kempton (1986) referred to this latter theory as an 'amateur theory' of home heating, as it is a simplistic version of the actual way the heating system works. Kempton (1986) described how different shared theories may predict different behaviour patterns of thermostat set point adjustment. He discovered that holders of valve theory, had a unique behaviour characteristic absent in those holding feedback theory. At night, valve theorists regularly set the thermostat back to below normal comfort levels, which Kempton (1986) described as 'night set back'. Kempton (1986) proposed that despite the 
valve theory being less accurate than the feedback theory, this behaviour characteristic was likely to result in greater energy savings overall.

Since Kempton (1986), additional shared theories of thermostat function have been proposed in the literature such as 'Timer' (Norman, 2002) and 'Switch' (Peffer et al.,2011). Users holding the timer theory are thought to select greater values of set point, when longer periods of boiler operation are desired. Those holding the switch theory are thought to use the thermostat merely as an on/off switch. Both of these theories assume the user, not the system, is responsible for maintaining a comfortable house temperature. Norman (2002) and Peffer et al. (2011), do not refer to studies which informed these types of shared theory, nor do they describe distinct behaviour characteristics which may influence energy consumption. When investigating current user mental models of home heating, the authors therefore consider it relevant to determine if these, or new shared theories of home heating, could be identified. Understanding how resulting shared theories associate with energy consuming behaviour could provide insights to inform novel approaches to reduce consumption.

The reader may question if Mental Models need to be accurate or is it sufficient that they are effective. Depending on context and the specific user behaviour being considered, what is considered 'effective' will vary. Kempton 1986 described how a faulty mental model of home heating control could lead to more energy efficient behaviour, than a more accurate model. Norman (1983) contends that designers and instructors should ensure a 'functional' (not necessarily accurate) mental model to enhance user interaction with a system. Norman (1986) emphasises that the appropriateness of the user's underlying model of a system is essential when troubleshooting, as the user is able to derive possible courses of action and possible system responses. Kieras \& Bovair (1984) concluded that for very simple devices or procedures, there will be little value in providing a device model to users. Manktelow and jones (1987) warn that systematic errors may result from an inappropriately simple mental model. So, taken together, the authors conclude that for simple procedures, simple devices or systematic errors that have minor consequences, a 'functional', simplified or even lack of mental model, may be effective. For more complex systems or procedures, where the need for troubleshooting is likely, or if the consequence of systematic errors is significant (as in the case of non-optimal home heating during an energy crisis), a more accurate user mental model may be needed for the effective use of devices.

Hancock and Szalma (2004), emphasised the importance of qualitative methods in revealing user intention in a way that can inform the development of design principles. Flyvbjerg (2011) argues that rich data gathered from detailed, real life situations can provide meaningful insights, that could not be gained from context-independent findings. Virzi (1992), R.A (1992), when conducting research into usability, found $80 \%$ of problems, including the most severe, are detected with the first 4-5 subjects, illustrating how key insights can be gained with very small samples. Hancock et al. (2009) also argue that ideographic case representations are increasingly relevant for the design of humanmachine systems, as advances in technology begin to focus on exploiting individual differences. Supporting these sentiments, this paper describes the results from an intergroup case study of home heating control, focusing in detail on 3 individual case studies taken from a pool of 6 . The intention of this paper is to: 1) Demonstrate the existence of distinct mental model descriptions of the functioning of present day UK home heating systems, that differ significantly from actual functioning. 2) Seek evidence of Kempton's (1986), Norman's (2002) and Peffer et al.'s (2011) shared theories of 
thermostat function in the case study group, and 3) discuss the present day relevance of Kempton's (1986) valve and feedback models of thermostat function, to design strategies targeted at combatting climate change. Additional implications and the limitations of the study are also discussed.

\section{Method}

\section{Participants and setting}

The case study group was non-randomly selected and comprised mainly overseas postgraduate students with families, new to the UK, who resided in semi-detached university owned accommodation in Southampton, UK. Participants arrived in their accommodation at the start of September 2011 and used the central heating system during the autumn and winter months. Southampton has an oceanic climate, with cool winters (temperatures typically below $50 \mathrm{C}$ ). The accommodation, home heating devices and levels of insulation were matched, so that variations in mental model descriptions could be attributed to characteristics of the participant, rather than the environment. The layout of the home heating devices and specific models used are shown in a diagram in Figure 1. The Participants were recruited by letter, email and approached door-to-door by the author. Permission was sought from the Faculty Ethics committee prior to contact and Research Governance was arranged. The participants that agreed to take part, were all from warm countries where centralised home heating devices are uncommon. This user group characteristics, whilst not originally sought by the authors, ensured minor experience of other home heating devices. This benefits the mental model descriptions of home heating systems, by making them more closely aligned to the specific home heating devices installed, rather than previous experience by the participants of other home heating devices. Insights from this case study could therefore use the specific design and layout of the setup as a starting point for energy saving strategies. 


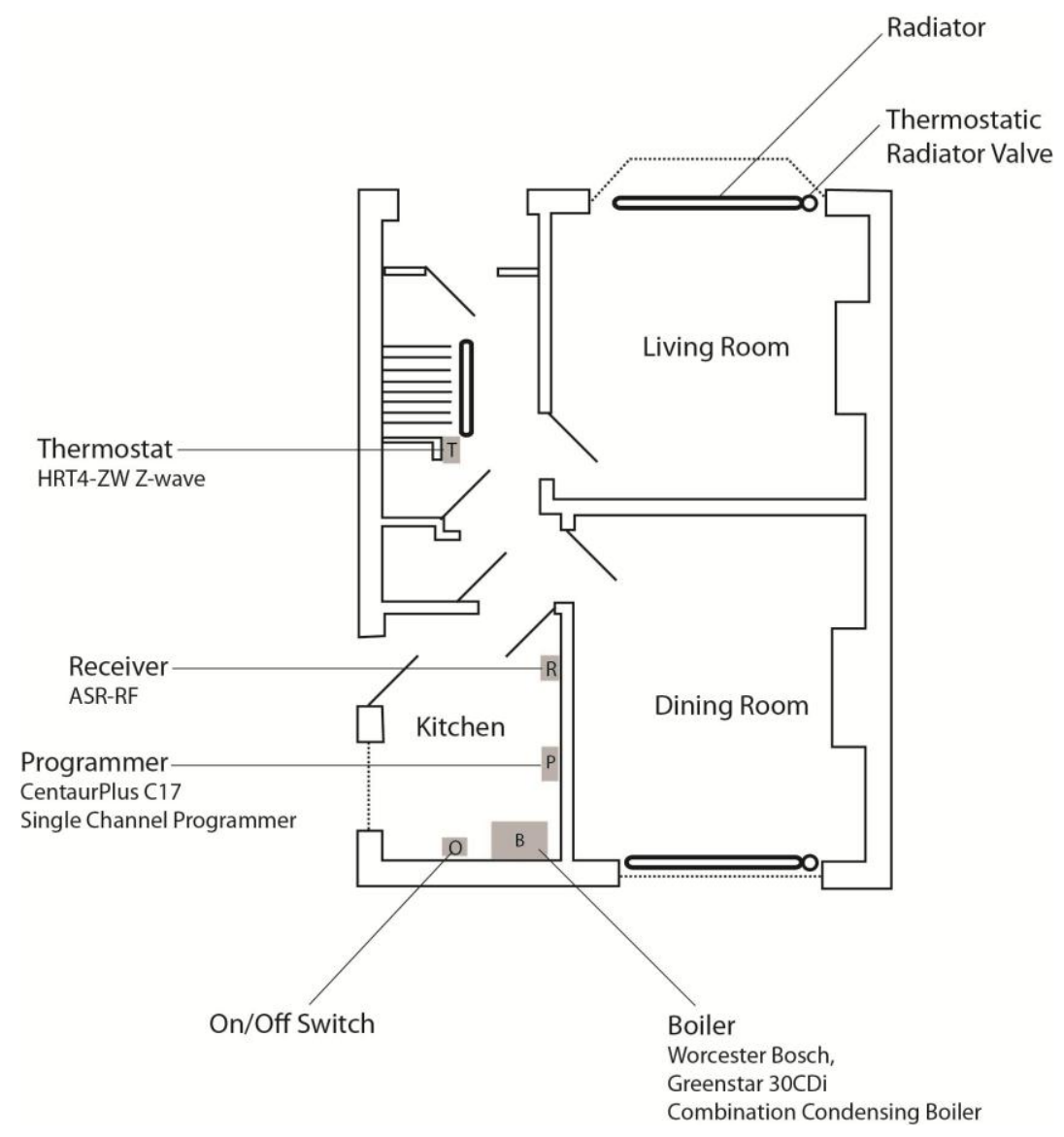

Figure 1 - The layout of the home heating devices and specific models used during the intergroup case study

\section{Data Collection}

The authors adopted a pragmatic worldview to their research. Whilst a postpositivism worldview is suggested by the objective to verify Kempton's (1986) shared theories of home heating, the authors ensured their data collection method allowed interpretations of the data beyond this scope. It was important to the authors that alternate shared theories or unique UMMs could be revealed. This would allow further understanding of people's mental models of home heating function to be gained, that could inform design based strategies (amongst others) for reducing energy consumption. A method adapted from Kempton (1986) and Payne (1991) was developed to these ends. Payne (1991) described 'shared theory' device models in a concrete diagrammatic form that the authors believed better communicates misunderstandings of function to design practitioners, than textual or nondeterministic schematic representations. Kempton $(1986 ; 1987)$ used in depth interviews and analysed the transcripts using metaphorical analysis (devised by Lakoff and Johnson ,1981). He provides recommendations on the interview process and example questions and probes specific to home heating systems. From this, an interview approach could be developed to access content that allowed the analyst to identify shared theories. The resulting method devised by the authors was a semi-structured interview that included a paper-based activity whereby the participant represented represent their device model in a concrete diagram form. For pragmatic application of mental models research, Revell \& Stanton, 2012, emphasised the importance of accuracy in the capture and representation of internal constructs. This accuracy requires the description of the mental model to reflect its source (in this study, the user of home heating systems), rather than assumptions by the recipient (e.g. the analyst). The risk of bias as a means of causing inaccuracy in mental model research, and the need to take pains to minimize bias is well documented in the literature (Rouse \& Morris 1986, Wilson \& Rutherford,1989, Bainbridge, 
1992, Richardson \& Ball, 2009, Revell \& Stanton, 2012). Revell \& Stanton (2012) developed a 'treering' method in order to identify risk of bias when conducting mental models research, resulting in an adaptable framework (presented in table format). This framework required specification of both the risk of bias and the type of knowledge structure, to aid commensurability (see Revell \& Stanton, 2012, for an example of the tree ring method applied to Kempton (1986) and Payne (1991) plus the resulting table). The tree-ring method (Revell \& Stanton, 2012) was applied to the approach devised for this study, and amendments were made to the data collection and analysis process in response to identified bias. The risk of bias identified through the tree ring method (Revell \& Stanton, 2012) related to: 1) The background experience of both the analyst and participant, 2) The social expectations and means of communication of both the analyst and participant, 3) The structure of cognitive artefacts used in the interview, and 4) The method of analysis of cognitive artefacts. These types of bias, and the strategy for mitigation or clarification are shown in table 1 . The leftmost column shows criteria to be specified, with the section labelled 'perspective of gathering data' standard in every table. The section labelled 'layers of risk of bias' is specific to the approach considered. The type and number of layers of bias, are dictated by the results of the tree-ring method. The middle column specifies the details required. Alphabetised in italics, are types of relevant bias that may need mitigation. The right-most column details how the approach adopted responded to the identified bias (also alphabetised). Table 1 allows readers to gauge the scope of efforts to promote accuracy in the capture of the UMM in the mental model description produced.

Table 1 - Risk of bias and mitigation strategy for method adopted, derived using tree-ring method from Revell \& Stanton (2012)

\begin{tabular}{|c|c|c|}
\hline $\begin{array}{l}\text { Perspective of gathering } \\
\text { data }\end{array}$ & \multicolumn{2}{|c|}{ Mental models in home heating control } \\
\hline Mental Model Description & \multicolumn{2}{|c|}{ Valve, Feedback as defined by Kempton (1986), Switch (Pfeffer et al.) } \\
\hline $\begin{array}{l}\text { Context (domain, } \\
\text { behaviour/task, goal) }\end{array}$ & \multicolumn{2}{|c|}{$\begin{array}{l}\text { Domain: Domestic } \\
\text { Behaviour: Patterns of adjusting thermostat dial, } \\
\text { Goal: Comfortable body temperature in a family home, reducing waste of energy/money }\end{array}$} \\
\hline $\begin{array}{l}\text { Mental Model Definition } \\
\text { used } \\
\text { (e.s. shared model, user } \\
\text { mental model, device model } \\
\text { etc.) }\end{array}$ & \multicolumn{2}{|l|}{$\begin{array}{l}\text { User mental model (Norman, 1983) } \\
\text { Shared theory (Kempton, 1986) } \\
\text { Device Model (Kieras \& Bovoir, 1984) }\end{array}$} \\
\hline $\begin{array}{l}\text { Source } \\
\text { (e.g Device user(s), Designer, } \\
\text { Analyst) }\end{array}$ & \multicolumn{2}{|c|}{ Users of domestic central heating systems in the UK } \\
\hline $\begin{array}{l}\text { Intermediaries } \\
\text { (e.g. Analyst(s), System Image, } \\
\text { Instructor) }\end{array}$ & \multicolumn{2}{|l|}{ Analyst } \\
\hline $\begin{array}{l}\text { Recipient } \\
\text { (e.g. Analyst, Designer, } \\
\text { Academic Community) }\end{array}$ & \multicolumn{2}{|c|}{$\begin{array}{l}\text { Academic Community interested in climate change, behaviour change, device design, psychology, human } \\
\text { factors }\end{array}$} \\
\hline Layers of 'Risk of Bias' & Intergroup Case Study & Mitigation Strategy in Method to address Bias identified \\
\hline $\begin{array}{l}\text { Source Background Ring (s) } \\
\text { (e.g. Number, defining } \\
\text { demographics, relevant } \\
\text { experience, Applicable bias) }\end{array}$ & $\begin{array}{l}\text {-Multiple (6) } \\
\text {-Recent residents in University of } \\
\text { Southampton Accommodation. } \\
\text { - Families with young children, recently } \\
\text { arrived to the UK from countries with } \\
\text { hot climates) } \\
\text {-Male \& female } \\
\text { A) Representativeness } \\
\text { B) Availability of scenarios }\end{array}$ & $\begin{array}{l}\text { A) Unusual user group allows mental model descriptions to } \\
\text { be attributed to interaction with specified devices, rather } \\
\text { than habit (Specific mental model descriptions cannot be } \\
\text { generalised to native UK population, however). } \\
\text { B) Questions regarding background of participant and } \\
\text { previous experience with central heating, added to interview. }\end{array}$ \\
\hline $\begin{array}{l}\text { Source Social Ring (s) } \\
\text { (e.g. Number, method of } \\
\text { communication, incentive, } \\
\text { applicable bias) }\end{array}$ & $\begin{array}{l}\text {-Multiple (6) } \\
\text {-Answers to structured interview based } \\
\text { on Kempton (1986) and Payne (1991) } \\
\text {-Concept map representing users } \\
\text { mental model description } \\
\text { A) Belief bias } \\
\text { B) Consistency bias }\end{array}$ & $\begin{array}{l}\text { A) Topic of study - method seeks user's beliefs of home } \\
\text { heating system function. } \\
\text { B) Positioning provided in interview that inconsistencies are } \\
\text { 'o.k' and expected, to reassure participants. } \\
\text { C) To prevent embarrassment, careful positioning reiterated } \\
\text { throughout interview that technical accuracy is not sought, } \\
\text { only how participant 'imagines' what is happening. }\end{array}$ \\
\hline
\end{tabular}




\begin{tabular}{|c|c|c|}
\hline & $\begin{array}{l}\text { C) Embarrassment of incorrect answer } \\
\text { D) Reluctance to offer 'ridiculous' } \\
\text { answer } \\
\text { E) Misunderstandings - not native } \\
\text { English speakers }\end{array}$ & $\begin{array}{l}\text { D) To encourage free discourse, participants told upfront, of } \\
\text { the opportunity to verify which parts of concept map they felt } \\
\text { 'sure' about, and which they were uncertain of. } \\
\text { E) Misunderstandings reduced by requiring subjects to have } \\
\text { good levels of spoken English. Paraphrasing by the analyst, } \\
\text { was used throughout, providing opportunities to check } \\
\text { understanding. }\end{array}$ \\
\hline $\begin{array}{l}\text { Analyst Social Ring (s) } \\
\text { (e.g. Number, access method, } \\
\text { applicable bias) }\end{array}$ & $\begin{array}{l}\text {-Single } \\
\text {-Semi-structured interview } \\
\text {-Concept map activity } \\
\text { A) Order bias } \\
\text { B) Belief bias } \\
\text { C) Experimenter bias } \\
\text { D) Confirmation bias } \\
\text { E) Leading by experimenter } \\
\text { F) Cueing }\end{array}$ & $\begin{array}{l}\text { A) Order bias acknowledged } \\
\text { B) Analysis table developed to encourage objective } \\
\text { categorisation, to mitigate for belief bias } \\
\text { C) Experimenter bias minimised by conducting interviews } 3 \\
\text { months after the study initiated, and taking care not to } \\
\text { provide subjects with information about their heating devices } \\
\text { that may alter their thinking/behaviour. } \\
\text { D) confirmation bias minimised by analyst avoiding exposure } \\
\text { to how the devices in the study function, ensuring participant } \\
\text { is required to fully explain their own thinking } \\
\text { E) leading minimised by analyst by providing semi-structured } \\
\text { interview template, and piloting interviews prior to data } \\
\text { collection. } \\
\text { F) Cueing minimised by using participant initiated } \\
\text { terminology and using plain paper (rather than a template) to } \\
\text { construct the concept map. }\end{array}$ \\
\hline $\begin{array}{l}\text { Analyst Background Ring } \\
\text { (e.g. Number, Defining } \\
\text { demographics, relevant } \\
\text { experience, analysis method, } \\
\text { applicable bias) }\end{array}$ & $\begin{array}{l}\text {-Single Analyst } \\
\text {-Psychology } \\
\text {-Design } \\
\text {-British } \\
\text {-compare user mental models } \\
\text { descriptions and transcripts to } \\
\text { Kempton's (1986) shared theories of } \\
\text { home heating. } \\
\text { A) Belief bias } \\
\text { B) Confirmation bias } \\
\text { C) Bias in interpretation of outputs }\end{array}$ & $\begin{array}{l}\text { A) To confront belief bias, analysts own bias accessed by } \\
\text { answering the interview questions prior to commencing } \\
\text { interviews. } \\
\text { B) To aid objective categorisation of individual mental models } \\
\text { with, an analysis table based on Kempton (1986;1987) was } \\
\text { constructed \& alternate interpretations to Kempton (1986) } \\
\text { were actively sought. } \\
\text { C) To minimise bias in interpretation, the mental model } \\
\text { diagram (that formed the basis for analysis), was constructed } \\
\text { with, and verified by, the participant. }\end{array}$ \\
\hline $\begin{array}{l}\text { Analyst Social Ring } \\
\text { (e.g. Number, applicable bias) }\end{array}$ & $\begin{array}{l}\text { Organisation of textual and } \\
\text { diagrammatic information for Academic } \\
\text { Community interested in climate } \\
\text { change, behaviour change, device } \\
\text { design, psychology, human factors } \\
\text { A) Bias - graphical \& descriptive } \\
\text { constraints of journal paper }\end{array}$ & A) Bias acknowledged \\
\hline $\begin{array}{l}\text { Analyst Cognitive Artefact } \\
\text { Ring } \\
\text { (e.g. Type(s), applicable bias) }\end{array}$ & $\begin{array}{l}\text { One-word analogous Textual } \\
\text { description. } \\
\text { Associated 'concept map' show key } \\
\text { components, and their relationship in } \\
\text { terms of links, cause and effect. } \\
\text { A) Bias- single view of mental model }\end{array}$ & $\begin{array}{l}\text { A) Specific view of mental model chosen to inform pragmatic } \\
\text { applicable to design / instruction }\end{array}$ \\
\hline
\end{tabular}

\section{Dynamics of the interview}

The interviews were undertaken in March 2012, in a library cafe at the University of Southampton, to comply with the requirements of the risk assessment. The informal, familiar setting helped place subjects at ease. Interview durations were approximately 1 hour, but varied depending on the level of detail provided by the participant, between 45 minutes and 1 hour 25 minutes. Interviews were recorded and transcribed by an independent transcription service. The interview comprised 3 main parts; 1) Background of participant, 2) Self report of user behaviour, and 3) Mental model of device function. For a full explanation of the development and examples of outputs and interview template, please see Revell \& Stanton (Under Review). In brief, part one covers the participants previous experience with home heating devices, determines if they have any formal training that may inform an 'expert' understanding the system, and captures the terminology they use when discussing the heating system in their home. Part two uses standard questions, probes and scenarios to help build up a diagram of 'typical use' of the participants heating system during a week. The final part, uses 
questions and follow on probes directed by the interview template, to build up a diagram with the participant. The diagram is built up using post-it notes containing the participant initiated terminology, as the analyst probes the participant to describe the relationship they exist between the components. Concepts are linked by drawing lines between the post-it notes with a pen (see figure 1 for an example of resulting output). To gain insights into cause and effect, and rules of operation, participants were asked follow-on probes such as "How does the boiler know when to come on/off" and "What would happen if you turned the thermostat to its maximum setting?". Participant responses to these probes were represented on the diagram using arrows and text (figure 1). Following completion of the diagram, the analyst paraphrased each component, link and rule depicted, so the participant was could verify if this represented what they imagined (marked with a smiley) or if they were uncertain this reflected what they really imagined (marked with a question mark). Participants were given the opportunity throughout the interview to amend the diagram to better reflect what they thought. These participant verified diagrams from part 3 of the method, represent the device topology and causal model of device function, which deKleer and Brown (1983) consider fundamental to mechanistic mental models. The form of the verified description is similar in form to a 'concept map'. They differ from simple concept maps as they contain written descriptions of rules and variables to enhance understanding of the users 'causal model'. This output is considered by the authors to reflect the device model held by the user, of their existing home heating system. Wilson \& Rutherford (1989) made the point that the outputs analysts capture when seeking a mental model is distinct from their actual mental model (an internal construct). Throughout this paper, that authors therefore refer to the participant verified diagram as their mental model description of home heating.

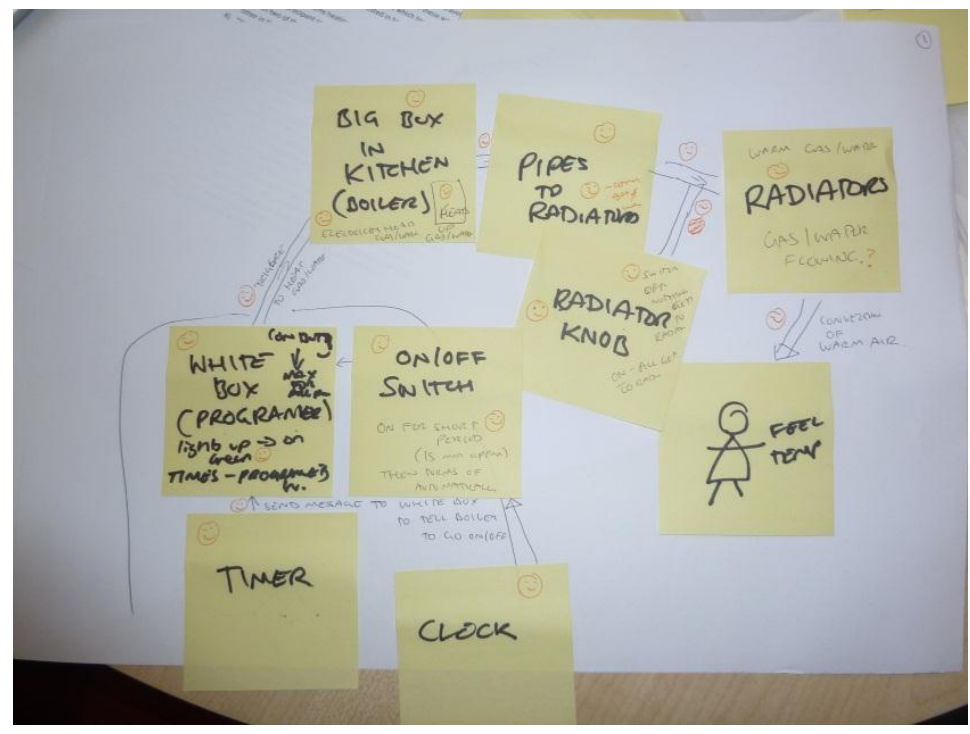

Figure 2 - Participant A's output from the paper-based activity, which formed the basis for analysis.

\section{Analysis of outputs}

These user verified mental model descriptions, and further evidence from the interview transcripts, formed the basis of discussion to determine aim 1; " if distinct mental model descriptions of thermostat function, that differ significantly from the actual functioning of UK heating systems, can be identified with present day UK heating systems". To determine if the shared theories described by Kempton $(1986 ; 1987)$ and others, are evident in the case study group, the interview transcripts were also examined. As the approach was designed with reference to the style and content of 
questions described by Kempton $(1986 ; 1987)$, the interview transcripts from the intergroup case study could be examined to find evidence of responses that met Kempton's (1986) criteria of either a feedback or valve shared theory.

To categorize data from the interview transcripts systematically, according to Kempton's shared theories, a reference table was developed (see table 2). Kempton (1986;1987, provided extended descriptions of valve and feedback model types. These descriptions were content analysed, identifying 4 distinguishing themes: 1) User Behaviour; 2) Thermodynamics; 3) Cause and Effect, and 4) Sensing/Control. For each of these themes, sub-themes with examples of participant responses considered (according to Kempton, 1986;1987) evidence of a particular theory, are shown in table 2. The authors were then able to systematically compare the meaning of participant responses in the inter-group case study to those in table 2, to determine if evidence of Kempton's $(1986 ; 1987)$ shared theories could be found.

Table 2 - AnalysisTable for categorizing responses from interview transcripts

\begin{tabular}{|c|c|c|c|}
\hline \multicolumn{2}{|c|}{ Themes } & $\begin{array}{l}\text { Typical responses from a thermostat user who } \\
\text { holds a Feedback Shared Theory (Kempton, 1986) }\end{array}$ & $\begin{array}{l}\text { Typical responses from a thermostat user who holds a } \\
\text { Valve Shared Theory (Kempton, 1986) }\end{array}$ \\
\hline \multirow{2}{*}{ 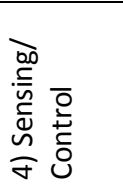 } & $\begin{array}{l}\text { Sensing } \\
\text { temperature }\end{array}$ & $\begin{array}{l}\text { - Thermometer (in thermostat) senses } \\
\text { temperature }\end{array}$ & - $\quad$ Human senses comfort \\
\hline & $\begin{array}{l}\text { Locus of } \\
\text { control }\end{array}$ & - $\quad$ System regulates & $\begin{array}{l}\text { - Human regulates - balances heat generated } \\
\text { with heat lost }\end{array}$ \\
\hline \multirow[b]{2}{*}{ 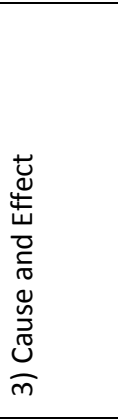 } & $\begin{array}{l}\text { Thermostat } \\
\text { set point - } \\
\text { cause and } \\
\text { effect }\end{array}$ & $\begin{array}{l}\text { Determines the 'on-off' temperature for the } \\
\text { furnace - furnace runs at a constant speed. }\end{array}$ & $\begin{array}{l}\text { Linear relationship - Controls the amount or } \\
\text { heat / rate of flow - furnace varies in its rate of } \\
\text { flow/amount of heat. }\end{array}$ \\
\hline & $\begin{array}{l}\text { Consequence } \\
\text { of different } \\
\text { set points }\end{array}$ & $\begin{array}{l}\text { - Small increase in set point - furnace on for } \\
\text { short time, then turn off } \\
\text { Large increase in set point - furnace run for } \\
\text { longer to reach the set point temperature } \\
\text { - Static set point - temperature maintained by } \\
\text { furnace switching on/off }\end{array}$ & $\begin{array}{l}\text { - Small increase in setting - small increase in rate } \\
\text { of flow/amount of heat. } \\
\text { Large Increase in setting - large increase in rate } \\
\text { of flow / amount of heat, } \\
\text { Decrease in setting - decrease in rate of flow / } \\
\text { amount of heat } \\
\text { Implication: confusion may occur if boiler turns off } \\
\text { itself. }\end{array}$ \\
\hline \multirow{2}{*}{ 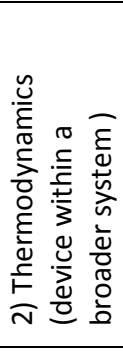 } & $\begin{array}{l}\text { External } \\
\text { temperature. }\end{array}$ & $\begin{array}{l}\text { - No impact, as thermostat will sense inside } \\
\text { temp and respond to maintain temperature. } \\
\text { Implication: confusion may occur if house seems } \\
\text { colder on colder days, or if comfort levels are low } \\
\text { despite usual set temperature }\end{array}$ & $\begin{array}{l}\text { - When weather is cold, house gets colder, so } \\
\text { user compensates by regulating the thermostat. }\end{array}$ \\
\hline & $\begin{array}{l}\text { Indoor } \\
\text { temperature } \\
\text { / }\end{array}$ & $\begin{array}{l}\text { - The effect of the house cooling down, means } \\
\text { more fuel is consumed when you increase } \\
\text { the heat again, than if you had left it at the } \\
\text { same setting. } \\
\text { Implication: No night set back }\end{array}$ & $\begin{array}{l}\text { - Impact of cold bodies not considered to have an } \\
\text { effect on energy used - More fuel is consumed } \\
\text { at higher settings than at lower ones, as the rate } \\
\text { of flow/temperature is higher. } \\
\text { Implication: Night set back }\end{array}$ \\
\hline 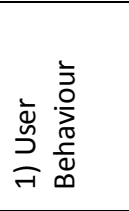 & $\begin{array}{l}\text { Pattern of } \\
\text { adjustment }\end{array}$ & $\begin{array}{l}\text { - Minimal adjustments over short period of } \\
\text { time. } \\
\text { Will change thermostat set point deliberately } \\
\text { at times when different levels of comfort are } \\
\text { required. Eg. different levels of occupancy or } \\
\text { activity. }\end{array}$ & $\begin{array}{l}\text { - Thermostat often changed between each hourly } \\
\text { datum. } \\
\text { - Thermostat is adjusted at least hourly whenever } \\
\text { someone is in the house. }\end{array}$ \\
\hline
\end{tabular}

The following process was adopted when analysing the transcripts, to aid reliability.

1. Examining sections 2, 3 and 4 of the interview transcript (self-report of behaviour, response to scenarios and device function), the type of responses by the participant were coded to separate 'meaningful responses by the participant' from 'confirmation of interviewers paraphrase'. The meaningful responses formed the pool for analysis. 
2. Each response in the pool for analysis was coded by the main themes in table 2. An 'other' category was used for responses that fell outside of these themes.

3. Using table 2, each response was evaluated as evidence of Kempton's (1986) shared theories. Whilst Norman (2002) and Peffer et al. (2011) did not provide sufficient descriptions to produce entries in table 2 for 'Timer' and 'Switch' models, the authors also considered if these models could be inferred from participant responses. The authors also point the reader to Revell \& Stanton (Under Review) where a reference table for quick analysis of diagram outputs from the method adopted, contains inferred responses for 'Timer' \& 'Switch' models. Responses were assigned to the following categories: 1) Feedback, 2) Valve, 3) Timer, 4) Switch, 5) Ambiguous and 6) N/A.

\section{Case studies}

Detailed individual case studies are presented of participants A, B \& C. These participants were chosen for this paper, as their mental model descriptions differed significantly from the actual function of the heating system in their home, as well as from the descriptions of each other. The remaining 3 participants from the pool of 6 , provided mental model descriptions with conceptual entities and their interrelationships broadly aligned to the actual functioning of the heating system, with a 'feedback' shared theory for the functioning of the thermostat. As the way users significantly misunderstand the functioning of the heating system is of interest in this study, the results from these participants will not be discussed in detail in this paper. Each case study will be presented with a description of the participant and their user verified mental model, redrawn for clarity. Discussion within each case study will focus on the consequence of differences in the content (in terms of elements /conceptual entities) and relationship (in terms of conduits between elements and rules of operation) of these mental model descriptions. How these differences influence user behaviour, and consequences in terms of energy consumption, will is also be discussed.

\section{Participant A: A Feedback mental model of thermostat with elements of Valve behaviour}

Participant A was a female housewife in her 30's. Originally from Malaysia, she lived with her student husband and two school age children. She and her husband both control heating in their home. Participant A's user verified mental model description of home heating is shown in figure 3. This has been redrawn for clarity and the different elements (in rectangles) have been coded according to the key, to distinguish user controls, the device benefit, and intermediary elements (between user control and device benefit). The arrows between the elements represent 'conduits' of either information or heat distribution. The thick line shows an example causal route between a user control and the device benefit. 
Participant A - Diagram of user verified mental mode description of home heating function, represented as 'elements and conduits'.

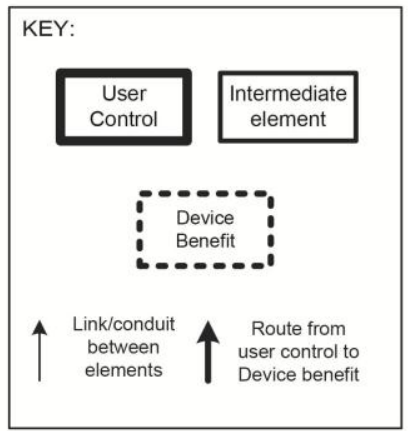

Transmitting 'on' message if set temp > room temp (green light turns on) Transmitting stops when room temp $=$ set temp (orange light turns on)
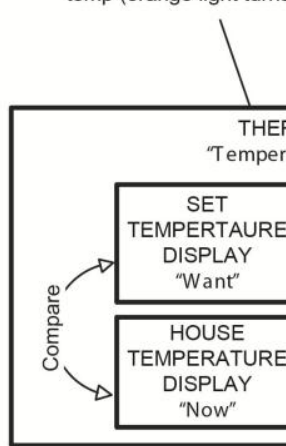

THERMOSTAT

"Temperature Control"

ON OFF SWITCH $S$ witch for Boiler (next to boiler)"
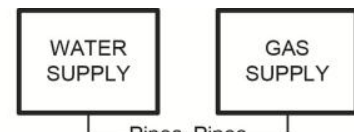

SUPPLY

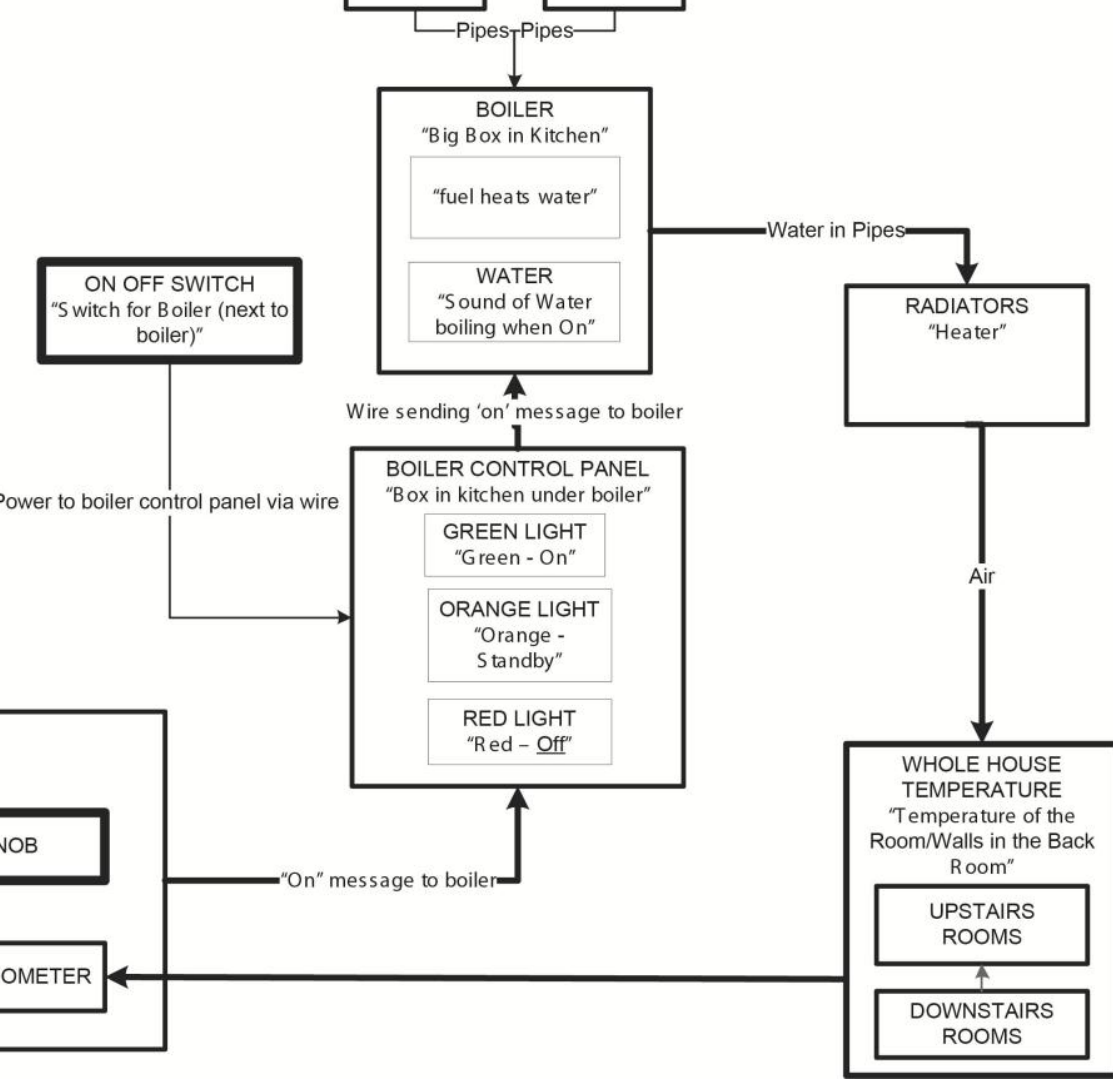

Figure 3 - Verified user mental model description of home heating for participant A

Looking at figure 3, the elements and conduits form a 'loop' shape, which immediately suggests a feedback model to the authors. The control devices include the thermostat knob and the main on/off switch for the heating system. When prompted, participant A was not aware of the existence of either the programmer device, nor the thermostatic radiators valves. Participant A described her goal when using the heating system, was to control the temperature of the whole house.

The second aim of this paper was to see if distinct mental models of home heating thermostat's could be categorized according to Kemptons' (1986) shared theories. To make analysis easier, the elements and conduits which form the causal path for the thermostat, have been redrawn in isolation, in figure 4. The left hand element is that which is controlled by the user, depicted with a 'hand'. Automation is represented with a 'robot head', and the rule for automation shown in a thought bubble. Other elements included in the causal path is shown with a square, and the benefit of using the home heating system is represented with a star shape.

The causal path shown in Figure 4 was further amended using evidence from the transcripts. The type of function to be performed by each element is indicated with an icon representing either a discrete or variable function, to give the reader a 'snapshot' of the relationship between elements. The relationship between these functions in specific scenarios provide insights into cause and effect (deKleer \& brown, 1983). The authors believe that an insight into the likely behaviour patterns of 
participant $A$ is gained by understanding how the relationship between these functions allow her to make predictions about the results of her actions.

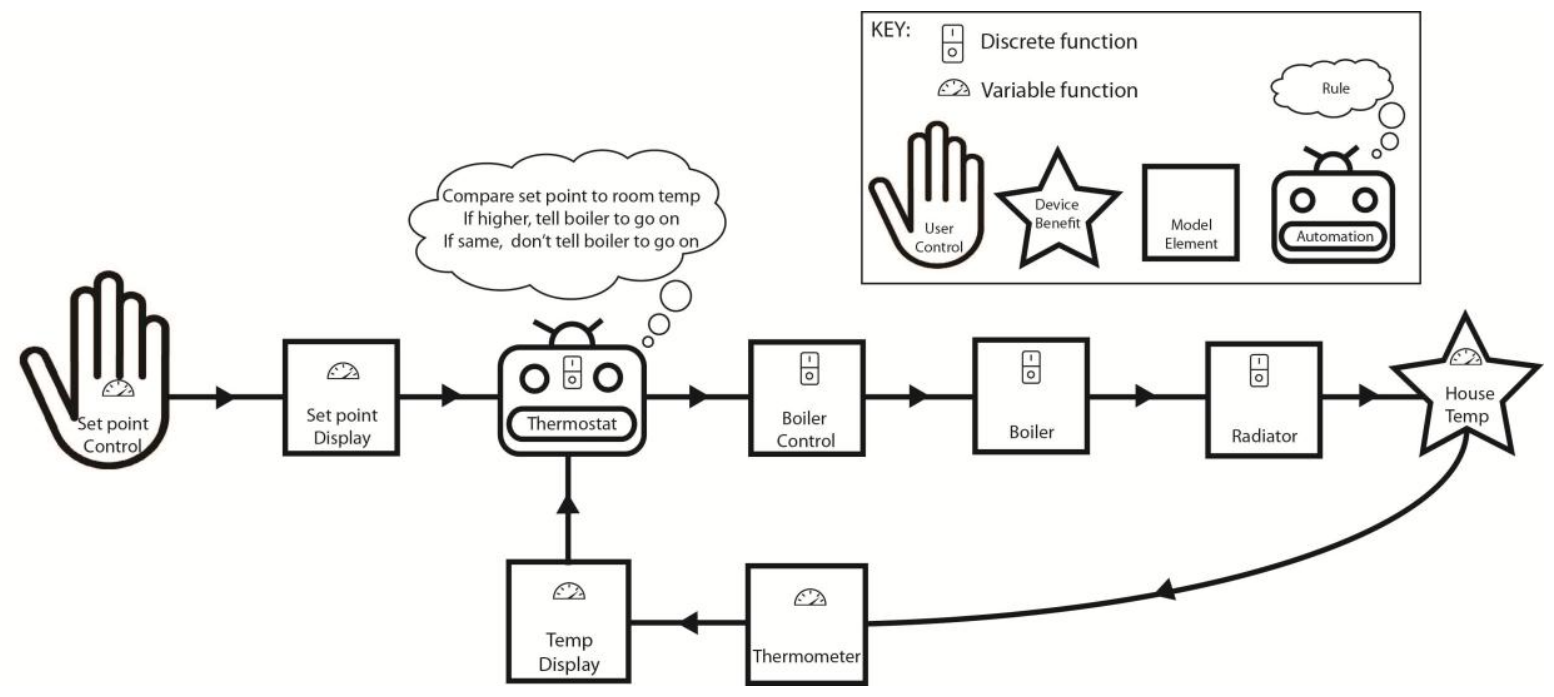

Figure 4 - Isolated causal relationship for thermostat knob taken from participant A's user verified mental model description of home heating.

Looking at figure 4, we can see that participant A's causal relationship includes a thermometer to sense the house temperature and that this feeds back data to the thermostat. The boiler is thought of as functioning like an automatic on/off switch, based on a rule whereby a comparison is made between the temperatures of the set point and house temperature. Referring to table 2, considering sensing temperature, locus of control and thermostat set point, the data from participant A clearly falls into the typical responses provided by a user holding a feedback model type. When considering the consequence of different set points, Participant A did not explicitly state that the furnace ran at a constant speed, but this is inferred by the authors since she only refers to discrete states of the boiler (on/off/standby) rather than variations in temperature or intensity. The boiler control (which is thought by the authors to be the programmer device) provides feedback on this status by different coloured lights. The quote below emphasises the boiler control is significant to her model of the boiler regulating the house temperature. When reading the transcript below, please note that that participant A initially favoured the term 'thermometer' for the entire thermostat unit. Square brackets in the transcriptions show the intended meaning.

Analyst: All right, so we've got this idea when you turn the thermometer [thermostat] up, it [programmer] goes green, normally it's on orange, which is our middle one. How does this going green affect what's happening in there? ....

PARTICIPANT A: When the temperature in the house probably down a bit then the temperature that we set, that's why it come green.

ANALYST: $\quad S o$ you're saying you've got the temperature that you set, which is from the thermometer [thermostat].

PARTICIPANT A: Yes, set and then maybe the temperature in the house getting colder a bit because of the outside maybe and then ..... automatically turn to green to make the house warm again to the set temperature. 
Participant A is also very clear about when the boiler automatically switches off, stating "It's nice and warm to the right temperature, it [the boiler] don't do anything." and "It [thermostat] will tell [the boiler] stop working!".

The first quote also considers thermodynamics relating to external temperature, showing again that the device, rather than the user, compensates for changes in external temperature. According to table 2 , this is a typical response from a user with a feedback shared theory.

In terms of patterns of adjustment (table 2), participant A initially provides clear evidence of a feedback shared theory. She reports adjusting the thermostat to deliberate set points corresponding to specific times relating to occupancy and activity, as we can see below;

ANALYST: $\quad$ And can you... do you happen to know what temperature you turn it up and down to?

PARTICIPANT A: At the evening, around 6 or 7, I tend to put it up to 23 then we go to sleep we keep it to 21. And, during the day, we normally keep it to 20.

ANALYST: $\quad$ So, at sleep it's 21, when you wake up in the morning, do you change it or do you just leave it until your children come home?

PARTICIPANT A: Well, usually I keep it to 20 because I want to keep the house warm because my kids go to school and then I keep it 20 because there is sun outside and if I'm in the lounge, it gets too hot.

There is an indication, however, that in certain conditions, in certain parts of the house, the device is not able to regulate house temperature sufficiently to maintain comfort, affecting participant A's set point choice. This is a response expected from a user with a valve shared theory (see table 2, external temperature). The thermostat used is positioned in the hall (see figure 1 ) in participant A's house, and actually takes air temperature readings at its location, influenced primarily by the heat output of the hall radiator. The transcript below reveals that participant $A$ imagines the inside temperature display represents the temperature of the 'whole house', rather than a single area.

ANALYST: $\quad$ And how does it know what the house temperature is?

PARTICIPANT A: Usually, the house temperature is... you're not touching anything by the small box you're talking about. If you just look at that, I think that is temperature of the room... of the house.

ANALYST: Of the house. So when you say the house, do you mean the walls, or...?

PARTICIPANT A: The whole house..

This misinterpretation in her mental model is significant in terms of her self-report of behaviour patterns. Whilst originally describing a regular routine for set point change, when provided with a typical scenario where comfort levels are too high, she revealed ad-hoc adjustments also occurred.

ANALYST: $\quad$ Next one scenario 3: The heating is on, you can feel the radiators are on but you've been rushing around doing housework or exercise or looking after the children or cooking and now you feel really hot and uncomfortable, what would you do?

PARTICIPANT A: I would scream my husband put it off! 
ANALYST: $\quad$ And when you say put it down, you mean this button [point to thermostat].

PARTICIPANT A: Yes, I tell my husband.

ANALYST: $\quad$ O.K. your husband.

PARTICIPANT A: Because I do exercise at home, I work out at home, I do my exercise at home.

ANALYST: $\quad$ How typical is this and how often would that happen?

PARTICIPANT A: Er, when I go to sleep, actually, every night. Because sometimes he has a habit to make it to 23. I think because he's sitting all the time. When I go upstairs to go to sleep, I scream you've got it so hot!

Further exploration revealed that this 'comfort battle' between her husband and herself, occurs regularly, during the day. If her husband is home, he frequently increases the thermostat set point to $22^{\circ} \mathrm{C}$, and she returns it to $20^{\circ} \mathrm{C}$. This pattern of behaviour is closer to that expected from a user who holds a valve shared theory (see table 1). Kempton (1986) stated that conflict battles may result in valve behaviour patterns. However, participant A reports that the battle occurs when she and her husband are located in different parts of their home, where thermodynamics of the house structure also effect comfort levels. As Participant A's believes the 'whole house temperature' is measured by the thermostat, it is logical, when considering the causal path in her mental model description (figure 4), that comfort would be regained by adjusting the set point, rather than a different strategy. More appropriate strategies, such as adjusting the thermostatic radiator valves to different settings to accommodate both her husband (studying downstairs) and herself (exercising, or sleeping upstairs) cannot be considered, as TRV's are absent from her mental model description of home heating (figure 1). As a result, heat energy is wasted by overheating rooms where a facility to limit the temperature to comfortable levels exists.

Participant A clearly provided a mental model description of thermostat function that fit the criteria derived from Kempton (1986) of a 'feedback' shared theory. Self reported planned, regular set point adjustments also fit the behaviour expected from a user holding this theory. Due to comfort conflicts, participant A reported behaviour patterns, which if viewed from set point measurements alone, would indicate a valve theory was held. However, the authors argue that this behaviour pattern is driven not just by 'comfort conflict', but by misinterpretations in the thermostat mental model, as well as an incomplete mental model description for the heating system as a whole.

\section{Participant B : Feedback behaviour without a feedback mental model}

Participant B is a female student in her late 20's. Originally from Mexico, she lives with her husband and young child. Participant B's mental model description for home heating is shown in figure 5 below. She is the sole operator of heating in her home. 


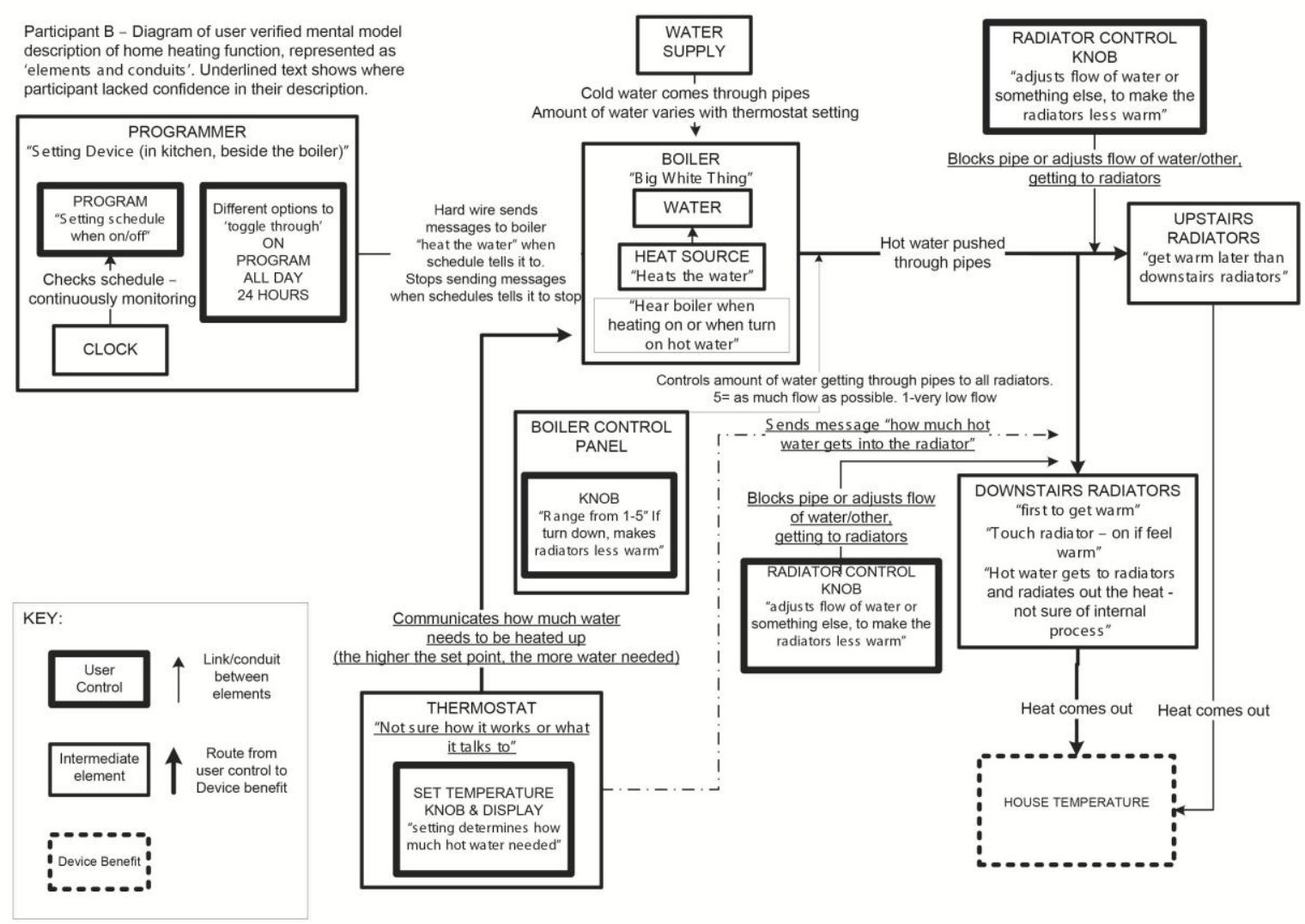

Figure 5 - Verified User mental model of home heating for participant B

We can see from figure 5 that the mental model description of home heating developed with participant $B$ is more complex and detailed than that for participant $A$. The shape contains no 'feedback' loop input to the thermostat device, which suggests the user does not hold a feedback shared theory of home heating. Participant B describes multiple control devices, including the program schedule, the override button, the thermostat set point control, boiler control knob and radiator control knobs (TRV's) for each radiator. The only heating control absent from this description is the power switch for the whole heating system. Participant B similarly described the purpose of using the heating system, was to warm the whole house. Figure 6 shows the causal path of the thermostat control, isolated from the other control devices, with icons added to represent the function of each element as inferred from the interview transcript. 


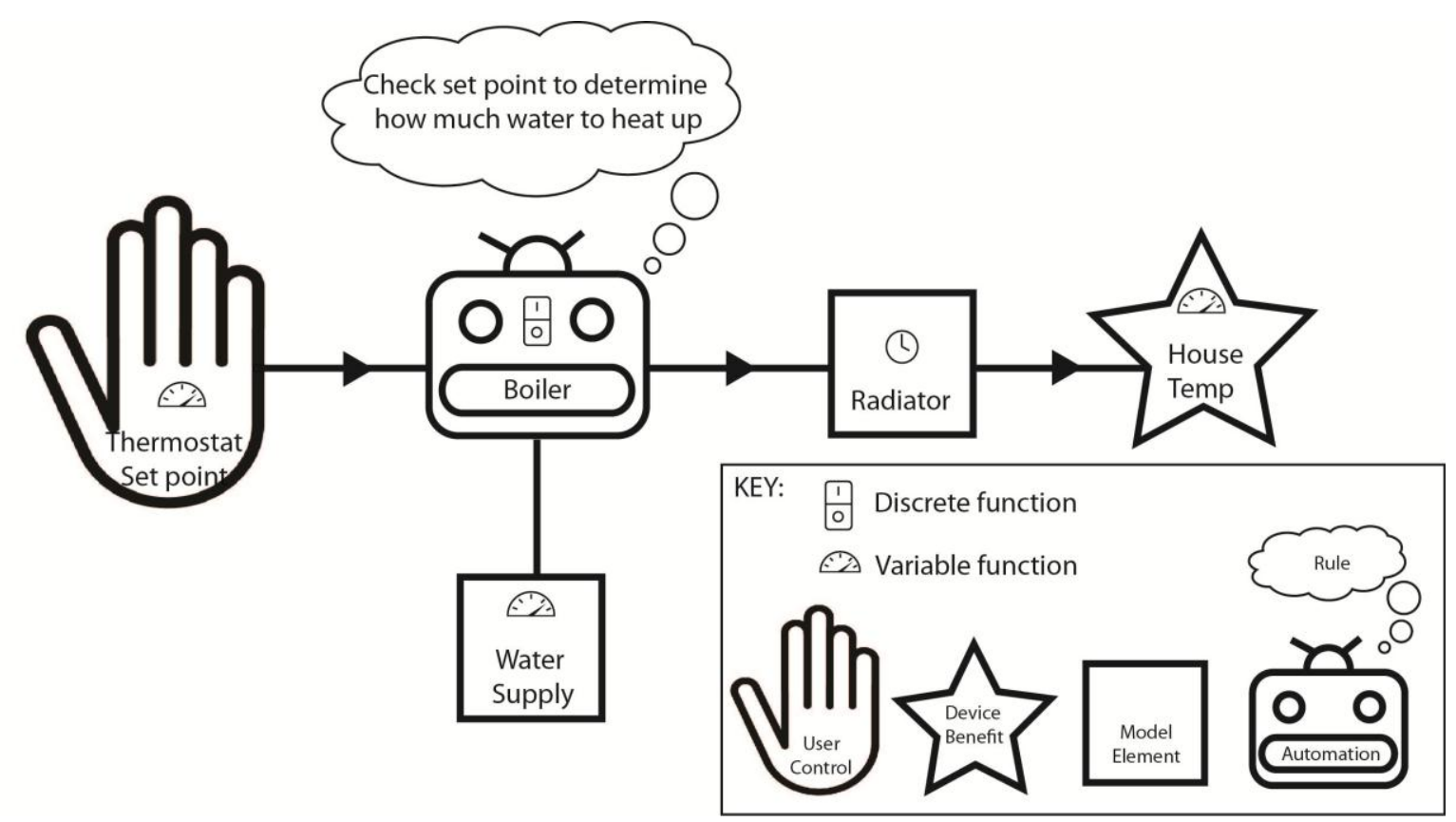

Figure 6 - Isolated causal relationship for thermostat set point taken from participant B's user verified mental model description of home heating.

Looking at figure 6, we can see that participant B's causal relationship for the thermostat set point is dependent on the water supply. There is no thermometer or feedback loop included in the mental model description by participant $B$. Variations in set point are matched with variations in the volume of water to be heated up by the boiler. In general usage, the boiler operates according to discrete states, automatically switching off when the corresponding amount of water has been heated. A larger volume of heated water ( following, according to participant B's model, from a higher set point value), takes a longer time period to run through the radiators, resulting in an a greater amount of radiated heat, and ensuring a higher house temperature.

When comparing figure 6 to the criteria in table 2, the lack of thermometer refutes a feedback theory being held. However, when responding to questions regarding the boiler override control, it appears participant $B$ is aware there is an inside temperature display on the thermostat device (see transcript below). She did not consider this of significance, however, when producing her mental model description of home heating (figure 5).

ANALYST: $\quad$...... what situations do you normally go in and press the button to get it to come on?....

PARTICIPANT B: $\quad$ Basically if I see the temperature is 16 or 17 degrees I feel it's a bit cold.

ANALYST: $\quad$ Okay. So even if you perhaps didn't feel cold but you noticed it was cold then perhaps turn it on, or is it only if you feel cold?

PARTICIPANT B: Yeah, I feel cold and then I check the temperature and say, "Okay, I'll turn -

ANALYST: $\quad$ So you making sure you really are cold?

PARTICIPANT B: Yeah, that it's not just me. (Laughs)

ANALYST: If you're cold. So you check... and that's on the thermostat?

PARTICIPANT B: Thermostat. 
This transcript clearly shows that participant B uses the device to determine if the house temperature is appropriate, rather than her own sense of comfort, which from table 2 is characteristic of a holder of a feedback, rather than valve, mental model. Considering cause and effect (figure 6), there is a clear linear relationship between the thermostat set point and the amount of water heated, suggesting a variation on the criteria for valve theory (table 2). We could consider participant B has a 'valve' theory, for the relationship between the thermostat with the water supply, but not with the boiler intensity.

ANALYST:.............. So what would happen then if you had the thermostat, like, up to 30 or something, if you had the thermostat at a really high temperature, the maximum temperature that you can go to, what do you think would happen?

PARTICIPANT B: $\quad$ Well then the boiler will have to produce more hot water and keep going and going through the radiators until they reach the temperature, I mean they make the temperature to 30.

ANALYST:So if 30 degrees is set on the thermostat lots of hot water is made Okay. Alright. What would you think would happen if you turned it right down to 5 degrees?

\section{PARTICIPANT B: The boiler will not operate}

A more appropriate analogy may be that each set point temperature has a fixed volume of water associated with it. When adjusting the set point, a message is sent to the boiler to select and heat up the corresponding volume of water. This also is clearly different from a feedback theory, whereby the boiler operates until the house achieves set point temperature, sensed by a thermometer. However, it may lead to similar behaviour, as it is accepted by participant $B$, that the system ensures, through this selection of water volume, that the desired house temperature will have been reached when the boiler deactivates. Continuous adjustments of thermostat set point would therefore be unnecessary. The consequence of different set points, when considering the relationship with water volume again can be interpreted as belonging to 'valve theory', as larger amounts of heated water result from larger increases in set point.

The transcript above, however, could also be interpreted as 'feedback theory' according to table 2, despite following from a mental model description that lacks a feedback loop. Heating larger volumes of water, assuming the boiler runs at a constant speed, also predicts the furnace will run for longer periods. When questioned, participant B was clear that the water temperature in the boiler was not raised by the thermostat, so a valve theory for boiler operation, as described by Kempton (1986) is refuted.

When questioned about her behaviour patterns when operating the thermsostat, participant B reported keeping the set point at a single value, relying on the programmer to regulate the heat. This behaviour again fits better with a response expected from a holder of a feedback, rather than valve, model (table 2).

ANALYST: Okay, so you're saying the thermostat's normally set at 20, sometimes you notice it's cold, would you then when you notice it's cold turn the thermostat up or just go to the programmer and press the programme?

PARTICIPANT B: Go to the programmer.

ANALYST:

Okay. is there any reason you would go and change through your

thermostat? 
ANALYST: No? Okay. So not during the week or weekends or holidays or anything like that, you would just keep it how it is and make everything controlled through the programmer?

PARTICIPANTB: Yeah.

A goal of this paper was to see if distinct behaviour patterns of thermostat function could be categorized according to Kempton's (1986) shared theories. This has been difficult to achieve with participant B's mental model description. Many traits which would be expected from a user holding a feedback theory were discovered. However, the concept of feedback, or temperature sensing was not present her verified mental model description (figure 5). The linear relationship between the thermostat set point and the water supply, was more akin to a valve theory, however it should be noted that this is not with the sense intended by Kempton (1986), which relates to heat flow or intensity in the boiler. Kempton (1986) suggested that users with a feedback shared theory could unnecessarily waste energy by avoiding 'night set back' of the thermostat. Participant B uses the programmer to limit consumption at night, so the need for night set-back is negated regardless of the theory held. The reasoning of feedback theory holders, according to Kempton (1986) (and summarised in table 1) is that it will take more energy to re-heat a cold house, than to maintain a warm house. This thinking is evident with Participant B in the following quote. From participant B's transcript, neither the thermostat or programmer settings are adjusted when away from the house at the weekend, or on holidays, suggesting energy is wasted by heating an unoccupied house.

PARTICIPANT B: Well I was actually thinking with that setting that I need... or that the house needs to be heated for not such a short time because maybe it will have to work more the next day. I mean to not leave the house unheated for a long period of time.

The desire to identify distinct mental models of device function, is to be able to predict user behaviour. Participant $B$, whilst using a deliberate thermostat set point, does not habitually make adjustments (preferring to use the programmer and override device). Figure 5 shows uncertainty in much of the mental model description relating to the thermostat device, with underlined areas show low confidence in the description. Participant B's mental model for thermostat function may be poorly developed, because she does not use the thermostat. On the other hand, participant B may not use the thermostat because her mental model of the thermostat is ambiguous or incomplete, undermining confidence in the outcome of her actions. The ability to predict behaviour patterns relating to user mental models of device function is necessary if design strategies to improve usability or influence behaviour are to be successful. This association is clearly more likely to be found when the participant actively uses the device under investigation.

\section{Participant C: Timer model for alternate control devices}

Participant $C$ was a female student in her 20's. Originally from Brunei, she lived with her husband, young child and father-in-law, and is the sole operator of the heating system. Figure 7 shows her user verified mental model description of home heating. 


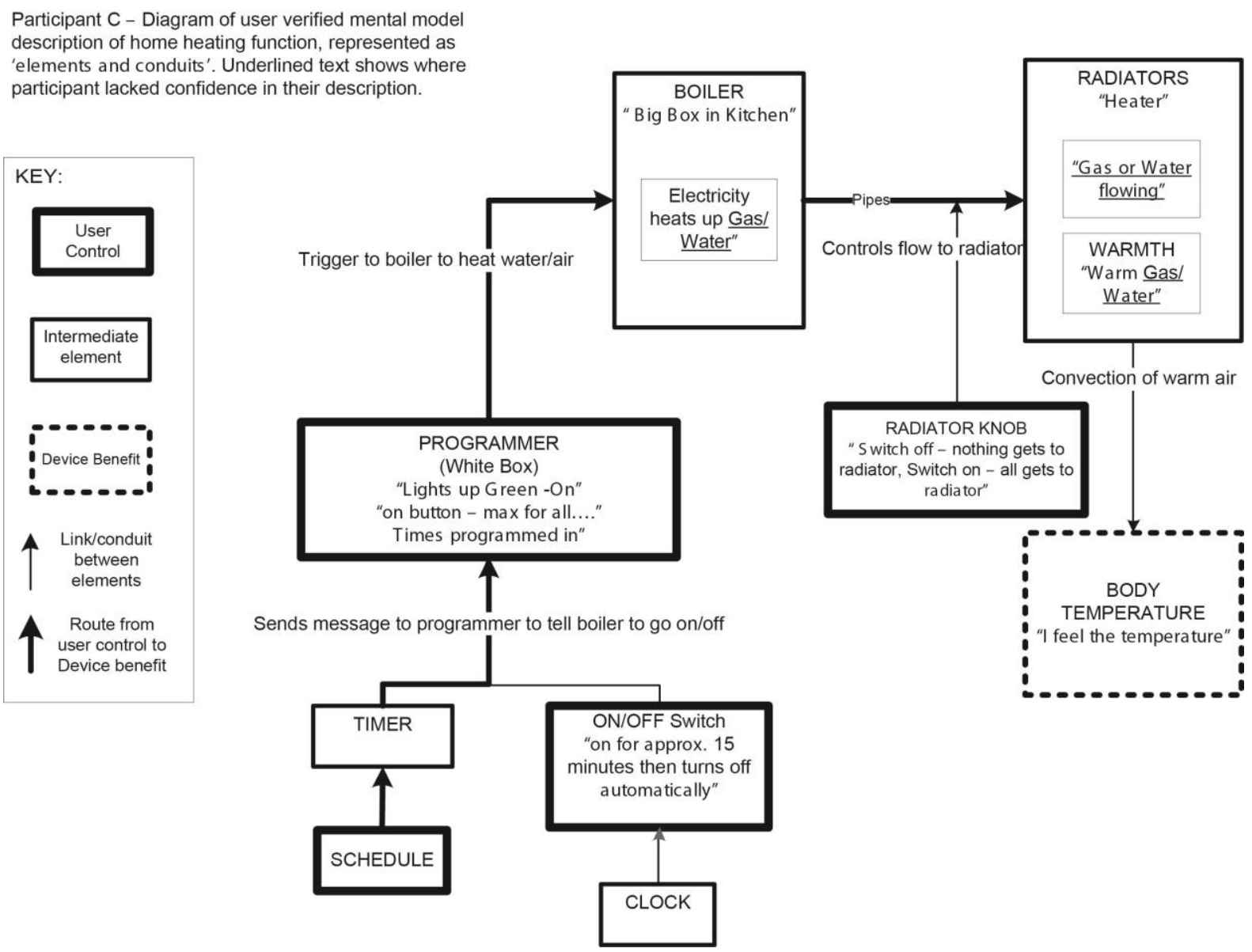

Figure 7 - User verified Mental Model description of home heating function, from participant C

Participant C's mental model description of home heating, is linear and branched in shape, and shows 3 different user controls; the schedule for the timer, the on/off (or override) switch for the programmer and the radiator knob (Thermostatic Radiator Valve (TRV)). The device benefit is not considered the house temperature, as with participants $A$ and $B$, but rather her own thermal comfort. Conspicuous by its absence is the thermostat device.

The second aim of this paper was to determine if mental model descriptions of thermostat function can be categorized according to the shared theory types in the literature. It is clear from the lack of thermostat device in figure 7, that this type of analysis couldn't be undertaken. To further the initial aim, that distinct mental model descriptions of home heating exist, two causal paths will be described from participant $\mathrm{C}$ of alternate control devices, as they provide further insights into the consequence of incomplete mental models. The causal path of the program schedule, and of the boiler override button are shown in figure $8 \& 9$. Unlike the previous causal paths, which focused on the thermostat, these include icons representing a time based variable.

Participant $\mathrm{C}$ clearly describes the programmer unit as a time based automatic switch, responsible for turning the radiators on and off;

"It is a digital device for the system to say at what time you want it to come on, and it will light up to yellow colour if the radiator is on and it will light up to red if the radiator is off, and it is automatically turned to on and off by the program" 
Figure 8 displays a linear route from manual input of the schedule to the resulting increase in body temperature, with the schedule function being time-based. The timer button (program option on the programmer), boiler and radiators are reported in the transcripts as being either 'on' or 'off' so function according to discrete, rather than variable states. This is an appropriate mental model for the programmer, if used in isolation. It is not clear from the transcript if the benefit, in terms of body temperature, is directly linked to the schedule, so an icon is absent from this element in figure 6.

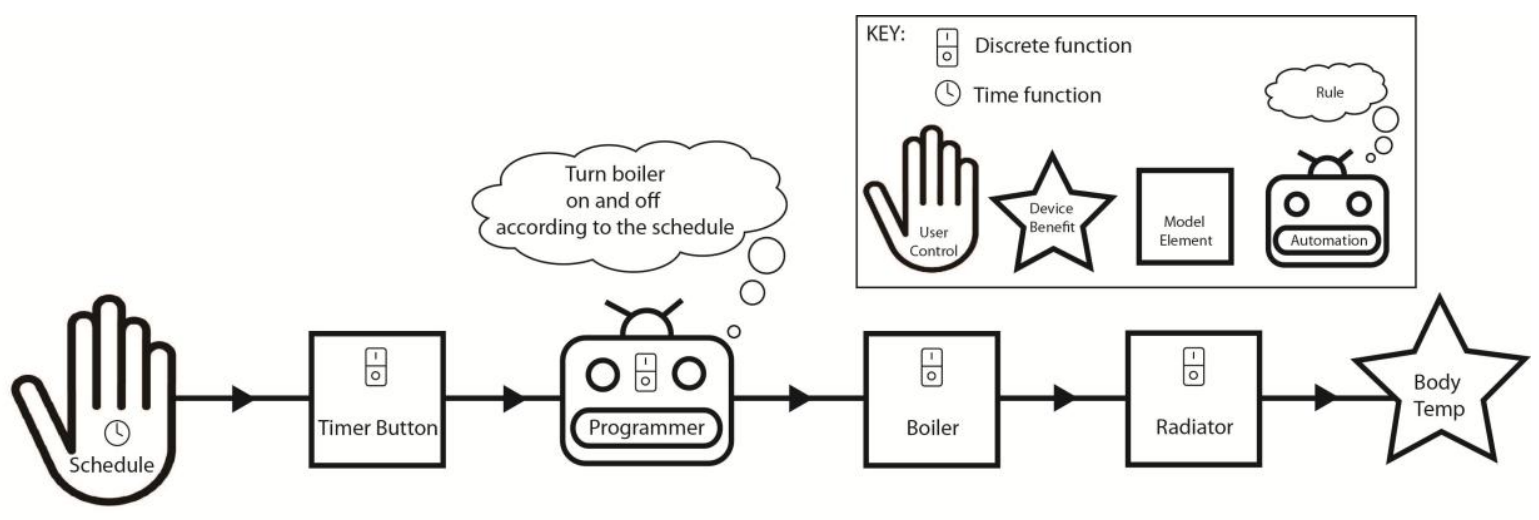

Figure 8 - Cause and effect route of schedule function for participant C

Figure 9 shows the cause and effect route for the override button for the programmer, which participant $\mathrm{C}$ referred to as the 'on/off' switch. This button allows the boiler to be activated outside of scheduled times.

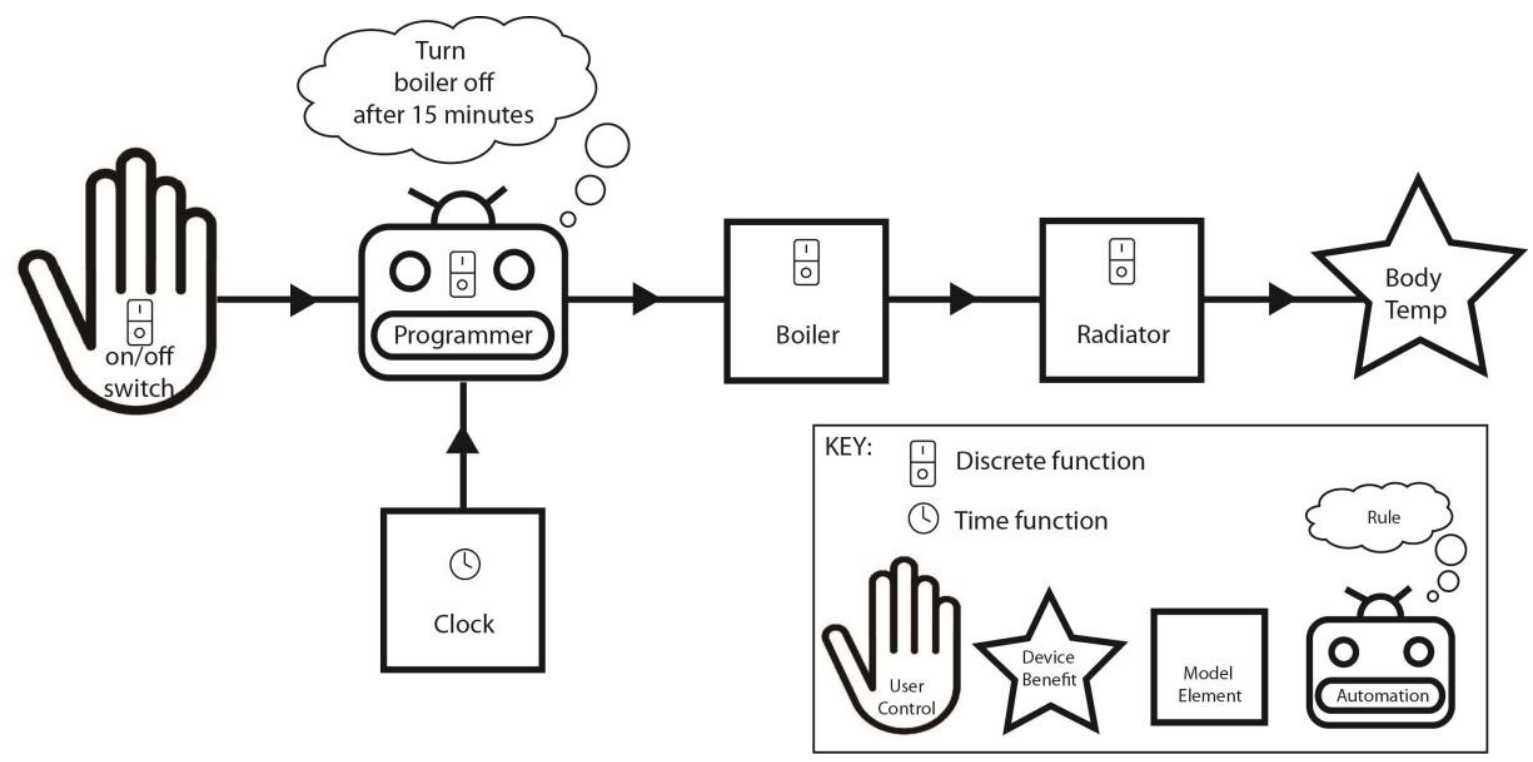

Figure 9 - Cause and effect depiction of override button for participant $\mathrm{C}$

Participant $\mathrm{C}$ reported that when using the override switch, the boiler switched itself off after approximately 15 minutes. The following transcript describe her confusion about this outcome. The blank lines represent parts of the conversation that have been omitted as they do not add new insights.

ANALYST: $\quad$ How do you think it knows when to come off? is it from the timer? Or something else that makes it switch off? 
PARTICIPANT C: It can't be the timer because the timer is already being programmed so it must be something else. It's by default it will just go off.

\section{ANALYST: $\quad$ So maybe after a certain period of time, or?}

PARTICIPANT C: Yeah.

ANALYST: Okay. So you've kind of got this idea about whenever you switch it on, it's almost like it's only on for a short period.

\section{PARTICIPANT C: Yes it doesn't obey me.}

From the last comment, it is clear that participant $C$ does not feel in control of the effects of this device. Further discussion led to the idea of a 'clock' telling the program when to switch off. The uncertain language used in the transcript above ("it must be", "it can't be") mean it is likely that this link was a construct of the interview, rather than the participants' existing mental model of the user (Payne , 1991). The authors argue that the need to add to a mental model to explain an unexpected phenomenon shows that the existing model of the system is not fully functional for this participant. Moray (1990) emphasised how it was not possible to troubleshooting problems successfully if the mental model held by a user, lacked the elements responsible for the problem source. It is likely that the true cause of the boiler deactivating a short period after the participant presses the override button, is the thermometer registering its surrounding air temperature equal to the thermostat set point (presumably set to a value below participant C's comfort levels). Since a thermostat device and thermometer are both absent from this participants mental model description (figure 7), this conclusion could not be arrived at by participant $\mathrm{C}$ herself.

Participant $\mathrm{C}$ relies on a daily schedule, which she believes ensures the boiler operates to produce heat for a short period in the morning, an hour for lunch, and a longer period in the evening. The schedule is repeated 7 days a week, regardless of changes in activity. When asked when she used the override button, participant $C$ revealed that she regularly overrides the system when the heating is scheduled to be on (between $5 \mathrm{pm}$ and $10 \mathrm{pm}$ ). Participant $C$ does not appear to see a conflict with her mental model of the timer, which is turning the boiler 'on and off' according to the schedule, and the need to override the program during scheduled 'on' times. She also admits to using an electric portable heater or "blower" to maintain or increase comfort levels between, or during scheduled times. These additional actions suggest that the home heating system with the existing schedule and (unknown) set point, fails to meet the comfort needs of participant $\mathrm{C}$. Depending on how energy hungry the model of portable heater, and the frequency and durations of operation, this strategy may result in higher levels of consumption than if the central heating had been set up to provide adequate comfort levels. However, it is possible, that this proximal ad-hoc heating from an alternate heat source is more energy efficient at meeting comfort needs, than if the whole house was heated for longer periods.

When provided with scenarios where her comfort levels are too low, participant $C$ provided a range of strategies unrelated to her mental model description of home heating (figure 7). These included washing hands, showering, putting on the portable heater, moving away from the window, putting on a blanket, and even lighting candles. The authors infer from this response that Participant $\mathrm{C}$ 
considers the central heating system in her home to be one of a range of solutions for achieving comfort, rather than the key solution. As her goal for using the heating is body temperature, rather than house temperature, it may be more appropriate to gain this participants mental model of comfort, rather than device function.

Whilst the lack of thermostat in participant C's mental model description meant is was inappropriate to evaluate if Kempton's (1986) shared theories were present, the authors examined the transcript for evidence relating to generic 'valve' or 'feedback' concepts. When participant C was asked how she knew the heating was on, she reported that "I will... first thing I will think house is warm", suggesting that she is sensing comfort, rather than referring to a device to get feedback of boiler activation. When describing how she though thermostatic radiator valves work, she similarly described valve thinking "The amount of the flow of the heating material flowing through the radiator. So if this is being turned on then there'll be more flowing into the radiator". There is no sense of variations in temperature or intensity of heat as a result of the heating system, however. Feedback concepts were completely absent from the transcript. For this participant, further exploration of timer mental models of home heating would be appropriate.

\section{Discussion}

A small scale intergroup case study was undertaken to identify : 1) If distinct mental models of the way home heating systems function could be found, that differ significantly from the actual functioning of UK systems, and 2) If these models could be categorized according to 'shared theories' of thermostat function from the literature. Data was collected from 6 participants in matched environments using a semi-structured interview including paper-based activities, developed by the authors (see Revell \&Stanton, 2012, and Revell \& Stanton, Under Review, for further details). The impetus for the research was to understand if the mental models held by individuals could explain their energy consuming behaviour in a way that could usefully inform strategies aimed at reducing consumption through behaviour change.

The authors found that 3 of the 6 participants produced mental model descriptions of their home heating system that differed significantly from the actual functioning of their system. The differences explained their self-reported behaviour with their home heating system, which, by association, may also explain their levels of energy consumption. From the mental model descriptions produced by the 6 participants, 4 represented thermostat function in a way that could be categorized according to Kempton's (1986) 'feedback' shared theory (a simplified version of the actual home heating functioning) . One participant described a variation of Kempton's (1986) 'valve' theory, and another participant omitted the thermostat device from her description, preventing comparable categorization. Timer and Switch shared theories for the thermostat, were found useful for categorizing user mental models of alternate home heating controls, such as the programmer and boiler override button. The valve shared theory could also be applied in a general sense to user mental models of the TRVs.

The key findings of this study, that add to the existing body of knowledge, are 1) that UMMs of thermostat function can be found that fall outside of the Feedback, Valve, Timer \& Switch shared theories described by Kempton (1986), Norman(2002) \& Peffer et al. (2011), and 2) omissions of entire control devices from UMMs of home heating, were evident despite an environment matched in terms of dwelling, and type and layout of home heating devices. In addition, (though not 
emphasised in the reporting of the three in depth case studies), thermostat set point adjustment was less prevalent than expected, with 4 out of the 6 participants reporting a reliance on other devices (e.g. programmer, override button and TRVs) when adjusting their home heating output. Finaly, the discrepency of the user's goal when using the heating system (e.g. heating the whole house or increasing the comfort of the occupant) and the actual benefit of the system (i.e. to produce a constant rate and intensity of heat, limited in period of operation by the program schedule, in activation by the thermostat set point, and in output by the TRVs set point) was also helpful when explaining reported confusion by the user, when operating the system.

In itself, the existence of UMMs that cannot be easily categorized according to existing shared theories is only important in terms of energy consumption, if the associated behaviour is significantly more or less 'wasteful'. In this study, the associated (self reported) behaviour of participant B closely matched that expected of users holding a 'feedback' theory, so participant B's specific UMM is not of special interest. However, consensus in the literature (e.g Kempton, 1986, Norman, 2002, Peffer et al., 2011, Richardson \& Ball, 2009) that UMMs fall into these categories of shared theory is challenged. This suggests that the existence of additional 'shared theories' or unique individual UMMs, that may have a significant impact in terms of energy consuming behaviour, cannot be ruled out.

The omission of control devices, rather than merely settings/options on a device, is an important finding. The omitted devices in our study included key controls, such as the programmer and thermostat, that hold a significant role in allowing the user to optimise energy consumption. The lack of key controls in UMMs affects the strategies that users can adopt in order to meet their goals. For example, it could impede users from achieving their desired level of comfort by being unaware they could adjust the thermostat or TRV setting, or that they could set the programmer to start heating before getting up). Alternatively, it could prevent users from reducing consumption by being unaware they could reduce the thermostat or TRV setting, or that they could set the programmer to automatically switch off at times when the home is typically unoccupied. A failure to meet user goals, as in the case of participant $\mathrm{C}$, who reverted to an electric heater when failing to meeting her comfort goals, could encourage alternate strategies that may be more costly in terms of energy consumption that optimal operation of the home heating system. In addition, the lack of key controls in UMMs of their own heating system, could hinder the success of advice based strategies to encourage reduced consumption in the home, when based on changes to the way users operate 'omitted' devices. For example, government advice in the UK to 'turn down your thermostat by 1 degree' (www.energysavingtrust.org.uk) would have little effect on participant $C$ in this study, who omitted the thermostat control when producing her mental model description of home heating.

Whilst the number in this intergroup case study are too small to indicate a trend, the preference of the majority of participants in this study to favour the programmer and boiler override devices to the thermostat, when asked about ad-hoc or routine adjustments, was surprising to the authors given an emphasis in the literature on thermostat behaviour styles (e.g. Kempton, 1986, Norman, 2002, Richardson \& Ball, 2009, Peffer et al., 2011). If large proportions of the general UK population also seek out alternate control devices to the thermostat, when making adjustments, it calls into question the present day relevance of Kempton's (1986) insight. It may no longer be important to consider user's 'shared theories' of thermostat function and associated behaviour patterns, as a means of understanding domestic energy consumption. However, this intergroup case study does 
suggest that a link between UMMs of home heating and their strategies for controlling heating are associated, so applying Kempton's (1986) insight at the system level, incorporating the integration of a range of control devices, rather than to a single control device, may be more appropriate.

When a user needs to translate their home heating goals (e.g. comfort, reduced consumption) in terms of the options available on the home heating system (e.g. home heating control set points, options \& schedule durations ), the ease of this translation is likely to effect optimal operation. This link between goals, mental models, strategies and performance is clear in the literature for interaction with devices (Norman , 1986) and within complex systems (Bainbridge, 1992, Moray 1990) In this case study, not only was there evidence of users not being able to meet their goals with Participants A \& C, but also a misunderstanding of the benefit, that the home heating system could provide (e.g. Participants A \& B, who thought the thermostat setting ensured the whole house was maintained at the chosen temperature). The authors believe that a better understanding of how to encourage optimal behaviour with home heating systems would benefit from considering not only how well the heating system can accommodate user goals, but also how appropriate users expectations were, of the heating system's benefit.

The data collection approach was chosen to achieve key objectives for this inter-group case study: 1) To encourage accuracy in the capture of UMMs by considering bias in interpretation in its development. 2) To capture a description of the user's device model. 3) to represent the users device model description in a concrete diagram form, to aid design based strategies. 4) to produce data that allows categorization of UMMs of thermostat function by existing shared theories in the literature, 5) To produce data that allowed alternate theories to be considered.

The method developed was intended to enhance previous methods of data collection from established researchers such as Kempton (1986) and Payne (1991) through mitigation of bias and reduction of ambiguity in the outputs. However, a systematic method of considering bias was used in the development of the method, with mitigating strategies or acknowledgement of bias stated in table 1. This provides readers with transparency so they can appreciate the steps undertaken to increase the chances that the captured mental model descriptions reflects the user, rather than the analyst. The paper-based element of the method was well suited in structure to capture users' device models of home heating. This concrete representation clearly identified missing elements and misunderstandings, providing emphasis for targetted strategies aimed at enhancing UMMs to encourage energy consuming behaviour.

In terms of capturing and depicting the users device model, the authors consider the process to develop and the resulting form of the user verified mental model description meets the objectives. Considering the methods ability to categorize UMMs according to shared theories in the literature, table 2 was helpful in categorizing according to Kempton's $(1986 ; 1987)$ feedback \& valve shared theories, but switch/timer shared theories needed to be inferred as Norman (2002) \& Peffer et al. (2011) gave insufficient information to populate the categories derived through content analysis of Kemptons's descriptions. However, the authors are confident that they did not overlook any evidence that the users held timer and switch theories for thermostat function in the intergroup case study. The concepts of timer/switch theories and Kempton's valve theory are clearly applicable to other home heating control devices in the study, both appropriately and inappropriately applied. A more generic (e.g. control device independent) definition of these theories would aid applicability 
to a range of energy consuming devices and could therefore have broader reach in understanding non-optimal user behaviour. The semi-structured style of the interview was beneficial in allowing participants to freely express ideas that were outside the scope of the shared theories from the literature. This was seen with participant B's variation on Kempton's (1986) Valve theory for the thermostat.

When researching mental models, as with any internal construct, there are limitation as it is not possible to directly assess and characterise the concept (Zhang et al., 2010). The method for extracting information and describing the user mental model will always be subject to bias based on the decisions, perspective and requirements of the analyst ( Zhang et al, 2010, Wilson \& Rutherford, 1989, Bainbridge, 1992, Revell \& Stanton, 2011). Revell \& Stanton (2011) argue that by systematically evaluating and stating the bias in data collection and analysis, the risk to bias for the resulting mental model description is explicit. This particular method necessarily accessed mental model subsequent to device use, due to the nature of the domain. As such there is risk of models being spontaneously created as part of the process (Payne 1991), although the language used and hesitancy of answer does provide an indication of this. The interview process itself gives an opportunity for the user to reflect upon and refine their mental model which is unavoidable. Nevertheless, refinements of a mental model that lacks key elements, or contains a misunderstood relationship between components through this process does not provide additional information that would allow misunderstandings to be corrected. The fundamental misunderstandings or emissions, rather than refinements on these understandings are most illuminating in terms determining strategies to encourage energy saving behaviour. There are clear challenges when trying to validate any internal construct, as direct access is not possible. Never-the-less, where there are clear absences of key components of the home heating system, in the mental model description, or unexpected interpretations of cause and effect, it is unlikely through the choice of probes and construction of diagrams, that the participant constructed an alternate view whilst actually holding a more accurate mental model of the heating system.

Another limitation of this research is the general applicability to a typical UK population due to the characteristics of the user group and the small sample size. This group's limited exposure to home heating was, however a benefit in being able to attribute the UMM descriptions to experiences with the devices present in the matched accommodation, rather than the extensive experience a typical UK resident would have. As the user group was in matched accommodation, it also means the device layout and model types can be considered a starting point from which to consider design based strategies to encourage behaviour change that take into account the misunderstandings and omissions seen.

Further work needs to be done with a larger sample size and more typical UK population to determine if the specific misunderstandings and omissions (in terms of the elements and relationships of components present in users device models of home heating systems) that were found in this intergroup case study are more generally applicable. A larger sample would also better indicate the current prevalence of existing shared theories from the literature, applied either to the thermostat, or more generically to alternate control devices. It may also reveal new shared theories to add to those already present in the literature. To understand if the device model or shared theory held, translates to significant differences in users energy consuming behaviour additional work needs to be done. A study that collects actual user behaviour with the typical range of home heating 
control devices, in addition to users device models of the home heating system could shed light on this relationship. There is presently much interest in to how to improve consumption with heating systems through design, focusing on programmable thermostats (e.g. Combe et al., 2011, Peffer et al., 2013), as well as investigation into the benefit of support aids for central heating (e.g. Sauer et al., 2009). The authors believe that the central heating system needs to be considered as just that, a system. Sauer et al., 2009, considers home heating to be the most complex system in the domestic domain. Consideration of individual control devices, in terms of usability is clearly important, but users need to be aware of which control devices to use in which situations, to fulfil their comfort and consumption goals. Support aids for central heating, or the redesign of central heating devices, that promoted a functional mental model to users of the integration between components of the heating system, could provide benefits beyond enhanced feedback or proscriptive guidance. The authors propose providing users with a pragmatic understanding of cause and effect for the multiple control devices presented on their heating system, that allows them to: a) relate their actions to their individual goals, and, just as importantly, b) understand when their individual goals cannot be met by the system. This could not only reduce consumption, but enhance comfort, providing the 'optimal consumption' we all seek.

\section{Conclusion}

Through comparison of user verified mental model descriptions of home heating, distinct mental models that differ significantly from the actual functioning of UK heating systems were shown.. Evidence of Kempton's (1986) feedback shared theory for the functioning of the thermostat was found. Other shared theories from the literature were useful in categorizing alternate control devices. A user mental model of the thermostat that could not be assigned to the existing shared theories in the literature was also found. Differences in the control devices present in mental model descriptions could explain confusion in operation. Differences in the causal path for specific control devices explained differences in reported behaviour. Variables such as the type and number of controllers and assumed device benefit appeared to interact with mental models of device function to explain reported behaviour. To apply the notion of mental models of home heating to encourage optimal energy consumption misunderstandings and omissions in user mental models could used to target design focus to encourage users to hold more integrated, functional models. Further work is needed to prove association between shared theories categorized by this method, and actual behaviour with devices, as well as methods for applying mental model descriptions in design strategies.

\section{Acknowledgement}

This research reported in this paper was supported by the Intelligent Agents for Home Energy Management project with funding from EPSRC (EP/I000143/1).

\section{References}

Climate Change Act 2008 [Online]. London: Department of Energy \& Climate Change Available: http://www.decc.gov.uk/en/content/cms/legislation/cc act 08/cc act 08.aspx [Accessed 10th November 2011].

2013. Thermostats and controls [Online]. Energy Saving Trust. Available: http://www.energysavingtrust.org.uk/Heating-and-hot-water/Thermostats-and-controls [Accessed 17th April 2013]. 
Bainbridge, L., 1992. Mental Models in Cognitive Skill: The Example of Industrial Process Operation. In: Rogers, Y., Rutherford, A. \& Bibby, P. A. (eds.) Models in the mind : theory, perspective and applications. London: Academic Press,111.

Baxter, G., Besnard, D. \& Riley, D. 2007. Cognitive mismatches in the cockpit: will they ever be a thing of the past? Applied Ergonomics, 38 (4), 417-23.

Branaghan, R. J., Covas-Smith, C. M., Jackson, K. D. \& Eidman, C. 2011. Using knowledge structures to redesign an instructor-operator station. Applied Ergonomics, 42 (6), 934-40.

Carroll, J. M., Olson, J. R., Anderson, N., University of Michigan. Cognitive, S. \& Machine Intelligence, L., 1987. Mental models in human-computer interaction : research issues about what the user of software knows, Ann Arbor: University of Michigan, Cognitive Science and Computer Science Laboratory.

Combe, N., Harrison, D., Dong, H., Craig, S. \& Gill, Z. 2011. Assessing the number of users who are excluded by domestic heating controls. International Journal of Sustainable Engineering, 4 (1), 84-92.

De Kleer, J. \& Brown, J. S., 1983. Assumptions and Ambiguities in Mechanistic Mental Models. In: Gentner, D. \& Stevens, A. L. (eds.) Mental Models. Hillsdale, New Jersey: Lawrence Erlbaum Associates,155-190.

Flyvbjerg, B., 2011. Case Study. In: Denzin, N. K. \& Lincoln, Y. S. (eds.) The Sage Handbook of Qualitative Research. 4th ed. Thousand Oaks, CA: Sage,301-316.

Hancock, P. A., Hancock, G. M. \& Warm, J. S. 2009. Individuation: the N=1 revolution. Theoretical Issues in Ergonomics Science, 10 (5), 481-488.

Hancock, P. A. \& Szalma, J. L. 2004. On the relevance of qualitative methods for ergonomics. Theoretical Issues in Ergonomic Science, 5 (6), 499 - 506.

Jenkins, D. P., Salmon, P. M., Stanton, N. A. \& Walker, G. H. 2010. A new approach for designing cognitive artefacts to support disaster management. Ergonomics, 53 (5), 617-635.

Jenkins, D. P., Salmon, P. M., Stanton, N. A., Walker, G. H. \& Rafferty, L. 2011. What could they have been thinking? How sociotechnical system design influences cognition: a case study of the Stockwell shooting. Ergonomics, 54 (2), 103-119.

Kempton, W. 1986. Two Theories of Home Heat Control. Cognitive Science, 10, 75-90.

Kempton, W., 1987 Two Theories of Home Heat Control. In: Holland, D. \& Quinn, N. (eds.) Cultural Models in Language and Thought. Cambridge: Cambridge University Press.,222-241.

Kieras, D. E. \& Bovair, S. 1984. The Role of a Mental Model in Learning to Operate a Device. Cognitive Science, 8 (3), 255-273.

Lakoff, G. \& Johnson, M., 1981. Metaphors we live by, Chicago: University of Chicago Press.

Larsson, A. F. 2012. Driver usage and understanding of adaptive cruise control. Applied Ergonomics 43 (3), 501-6.

Lockton, D., Harrison, D. \& Stanton, N. A. 2010. 'The Design with Intent Method: a design tool for influencing user behaviour'. Applied Ergonomics, 41 (3), 382-392.

Mack, Z. \& Sharples, S. 2009. The importance of usability in product choice: A mobile phone case study. Ergonomics, 52 (12), 1514-1528.

Manktelow, K. \& Jones, J., 1987. Principles from the psychology of thinking and mental models. In: Gardiner, M. M. \& Christie, B. (eds.) Applying cognitive psychology to user-interface design. Chichester: Wiley,83-117.

Moray, N. 1990. A lattice theory approach to the structure of mental models. Philosophical Transactions of the Roval Society of London, B (327), 577-583.

Norman, D. A., 1983. Some Observations on Mental Models. In: Gentner, D. \& Stevens, A. L. (eds.) Mental Models. Hillsdale, New Jersey: Lawrence Erlbaum Associates,7-14.

Norman, D. A., 1986. Cognitive Engineering. In: Norman, D. A. \& Draper, S. W. (eds.) "User Centered System Design: New Perspectives on Human-Computer Interaction". Hillsdale, NJ: Lawrence Erlbaum Associates,31-61.

Norman, D. A., 2002. The Design of Everyday Things, New York: Basic Books. 
Payne, S. J. 1991. A descriptive study of mental models. Behaviour \& Information Technology, 10 (1), 3-21.

Peffer, T., Daniel, P., Marco, P., Cecilia, A. \& Alan, M. 2013. Facilitating energy

savings with programmable thermostats: evaluation and guidelines for the thermostat user interface. Ergonomics, 56 (3), 463-479.

Peffer, T., Pritoni, M., Meier, A., Aragon, C. \& Perry, D. 2011. How people use thermostats in homes: A review. Building and Environment, 46, 2529 - 2541.

Rafferty, L. A., Stanton, N. A. \& Walker, G. H. 2010. The famous five factors in teamwork: a case study of fratricide. Ergonomics, 53 (10), 1187-1204.

Revell, K. M. A. \& Stanton, N. A. 2012. Models of models: filtering and bias rings in depiction of knowledge structures and their implications for design. Ergonomics, 55 (9), 1073-1092.

Richardson, M. \& Ball, L. J. 2009. Internal Representations, External Representations and Ergonomics: Toward a Theoretical Integration. Theoretical Issues in Ergonomics Science, 10 (4), 335-376.

Rouse, W. B. \& Morris, N. M. 1986. On Looking Into the Black Box: Prospects and Limits in the Search for Mental Models. Psychological Bulletin, 100 (3), 349-365.

Sauer J, Wastell Dg \& C., S. 2009. Designing for the home: a comparative study of support aids for central heating systems. Applied Ergonomics, 40. (2), 165-74.

Virzi, R. A. 1992. Refining the Test Phase of Usability Evaluation: How Many Subjects Is Enough? Human Factors: The Journal of the Human Factors and Ergonomics Society, 34 (4), 457-468.

Weyman, A., O'hara, R. \& Jackson, A. 2005. Investigation into issues of passenger egress in Ladbroke Grove rail disaster. Applied Ergonomics, [Special Issue: Rail Human Factors] 36, (6), 739-748.

Wickens, C. D., 1984. Engineering psychology and human performance, London: Merrill.

Williges, R. C. 1987. The Society's Lecture 1987 The Use of Models in Human-Computer Interface Design. Ergonomics, 30 (3), 491-502.

Wilson, J. R. \& Rutherford, A. 1989. Mental Models: Theory and Application in Human Factors. Human Factors, 31 (6), 617-634.

Zhang, T., Kaber, D. \& Hsiang, S. 2010. Characterisation of mental models in a virtual reality-based multitasking scenario using measures of situation awareness. Theoretical Issues in Ergonomics Science, 11 (1-2), 99-118. 